\title{
Efeito da remoção de folhas no desenvolvimento vegetativo e na produção do algodoeiro(1)
}

\author{
Aleksandra Gomes Jácome ${ }^{(2)}$, José Janduí Soares ${ }^{(2)}$, Rosa Honorato de Oliveira(2) \\ e Francisco Pereira Cordão Sobrinho(2)
}

\begin{abstract}
Resumo - O objetivo deste trabalho foi avaliar o efeito da remoção das folhas da haste principal e dos ramos frutíferos no desenvolvimento vegetativo e produção do algodoeiro (Gossypium hirsutum L.), cultivar CNPA 7H em casa de vegetação. A remoção das folhas da haste principal do algodoeiro reduz a altura das plantas, a área foliar, o diâmetro do fruto e do caule e principalmente a produção de frutos nas primeiras e segundas posições-chaves de frutificação.
\end{abstract}

Termos para indexação: Gossypium hirsutum, área foliar, caule, etapas de desenvolvimento da planta.

\section{Effect of leaf remotion on vegetative development and production in cotton}

\begin{abstract}
The objective of this work was to evaluate the effect of the removal of the leaves of the main stem and of the fruitful branches on the vegetative development and production of cotton (Gossypium hirsutum L.), cultivar CNPA 7H, in greenhouse. According to results, removal of the main leaves reduces the plant height, leaf area, fruit and stem diameter and mainly the production of fruits in the first and second fruiting positions.
\end{abstract}

Index terms: Gossypium hirsutum, leaf area, stems, plant developmental stages.

\section{Introdução}

De acordo com Ashley et al. (1965) e Jensen (1986) a produção das culturas é limitada pela área foliar, disposição das folhas, envolvendo o ângulo foliar e distribuição vertical macrofoliar, e a quantidade de $\mathrm{CO}_{2}$ existente na atmosfera. As folhas da haste principal são as principais responsáveis pela nutrição do ramo e dos frutos, principalmente nos nós abaixo do nono ramo frutífero (Wullschleger \& Oosterhuis, 1990). Beltrão \& Azevedo (1993) observaram que ao retirar as folhas da haste principal houve uma redução na produção de mais de $30 \%$ e o desenvolvimento da planta foi afetado.

\footnotetext{
(1) Aceito para publicação em 22 de setembro de 2000.

(2) Embrapa-Centro Nacional de Pesquisa de Algodão (CNPA), Caixa Postal 174, CEP 58107-720 Campina Grande, PB E-mail: soares@cnpa.embrapa.br
}

O curuquerê-do-algodoeiro (Alabama argillacea, Hueb. 1818), considerada a praga mais importante do algodoeiro (Soares et al., 1997), depois do pulgão (Aphis gossypii, Glover, 1876), alimenta-se, inicialmente, das três primeiras folhas da haste principal, e como até os 45 dias de idade as plantas não suportam redução da área foliar, ocorrem quedas na produção (Cavalcante, 1977; Cavalcante \& Cavalcante, 1981; Silva et al., 1981; Bleicher et al., 1983). Segundo Calafiori et al. (1986), caso a praga não seja controlada, ocorre o depauperamento da planta e a conseqüente queda de produção, fazendo com que as maçãs amadureçam precocemente, comprometendo as fibras e a qualidade das sementes.

Objetivou-se, com este trabalho, avaliar o efeito da remoção das folhas da haste principal e das folhas dos ramos frutíferos no desenvolvimento vegetativo do algodoeiro. 


\section{Material e Métodos}

O trabalho foi realizado na base física da EmbrapaCentro Nacional de Pesquisa de Algodão (CNPA), Município de Campina Grande, PB, em casa de vegetação, em dois experimentos, sendo a primeira semeadura realizada no dia 8 de abril de 1995, e a segunda, em 8 de março de 1996.

Ambos os experimentos tiveram delineamento experimental inteiramente casualizado, com três tratamentos e dez repetições. A cultivar utilizada foi a CNPA 7H, desenvolvida na Embrapa-CNPA. Tem como característica principal os ramos frutíferos mais longos que os de algumas cultivares, como a cultivar Precoce 2 . Foram utilizados vasos de plástico preenchidos com $10 \mathrm{~kg}$ de solo, proveniente do Município de Souza, PB, previamente destorroado e adubado, conforme indicação da análise de solo. Semearam-se cinco sementes, por vaso. Os tratamentos utilizados foram: remoção das folhas da haste principal ou ramo; remoção das folhas dos ramos frutíferos; sem remoção de folhas. A remoção das folhas da haste principal - simulando o ataque do curuquerêdo-algodoeiro - foi feita à medida que iam surgindo, durante o ciclo vegetativo, após sua identificação. A remoção das folhas do ramo frutífero iniciou com a primeira folha e terminou quando as plantas pararam de crescer.

No primeiro experimento (1995), o desbaste ocorreu 25 dias após o plantio, deixando-se duas plantas por vaso; no segundo experimento (1996), procedeu-se a outro desbaste aos 35 dias, deixando uma planta por vaso.
No primeiro experimento, foram medidos a altura das plantas e o diâmetro caulinar aos 40,60 e 110 dias após a emergência (DAE) das plântulas. No segundo experimento, a altura da planta e o diâmetro caulinar foram avaliados aos 40, 60, 80 e 110 dias. A área foliar foi medida, em ambos os experimentos, aos 40,60, 80 e 110 dias após a emergência, nas mesmas plantas. Os cálculos da área foliar foram realizados mediante a fórmula $\log \mathrm{y}=0,045+$ 1,910 $\log \mathrm{x}$ (onde: $\mathrm{x}$ é o comprimento da folha e y é a área foliar). Foram medidos, além desses parâmetros, a fitomassa, em 1995, a produção por planta, em 1996, e o número de frutos, nos dois experimentos. Para controlar o pulgão, foram feitas pulverizações com thiometon $250 \mathrm{CE}$, na dose de $65 \mathrm{~g} \mathrm{ha}^{-1}$ de ingrediente ativo. A irrigação foi efetuada segundo a necessidade hídrica das plantas. A análise dos dados foi realizada de acordo com Pimentel-Gomes (1987).

\section{Resultados e Discussão}

No primeiro experimento, a remoção das folhas dos ramos frutíferos não interferiu no crescimento do diâmetro caulinar, mas a remoção das folhas da haste principal reduziu o diâmetro do caule e a altura das plantas a partir dos 40 e 60 dias após a emergência das plântulas, respectivamente (Tabela 1). Este resultado confirma a importância da folha principal para o desenvolvimento vegetativo da planta de algodão, e conseqüentemente, para a formação e retenção dos frutos nos dois primeiros pontos de

Tabela 1. Efeito da remoção das folhas da haste principal e dos ramos frutíferos, em diferentes dias após a emergência (DAE), sobre o diâmetro caulinar e altura da planta do algodoeiro CNPA 7H, em experimentos realizados em $1995 \mathrm{e}$ 1996. Campina Grande, $\mathrm{PB}^{(1)}$.

\begin{tabular}{|c|c|c|c|c|c|c|c|c|}
\hline \multirow[t]{2}{*}{ Tratamento } & \multicolumn{4}{|c|}{ Diâmetro caulinar $(\mathrm{cm})$} & \multicolumn{4}{|c|}{ Altura de plantas $(\mathrm{cm})$} \\
\hline & $40 \mathrm{DAE}$ & $60 \mathrm{DAE}$ & $80 \mathrm{DAE}$ & $110 \mathrm{DAE}$ & $40 \mathrm{DAE}$ & $60 \mathrm{DAE}$ & $80 \mathrm{DAE}$ & $110 \mathrm{DAE}$ \\
\hline & \multicolumn{8}{|c|}{1995} \\
\hline Rem. das folhas da haste principal & $6,08 \mathrm{a}$ & $8,30 \mathrm{a}$ & - & $9,50 \mathrm{a}$ & $34,40 \mathrm{a}$ & $42,32 \mathrm{a}$ & - & $50,56 \mathrm{a}$ \\
\hline Rem. das folhas de ramos frutíferos & $7,12 b$ & $10,00 \mathrm{~b}$ & - & $10,30 \mathrm{ab}$ & $37,00 \mathrm{a}$ & $77,87 \mathrm{~b}$ & - & $88,80 \mathrm{~b}$ \\
\hline Sem remoção de folhas & $6,78 b$ & $10,40 \mathrm{~b}$ & - & $10,80 \mathrm{~b}$ & $37,50 \mathrm{a}$ & $73,60 \mathrm{~b}$ & - & $83,15 b$ \\
\hline $\mathrm{F}$ & $0,06 * *$ & $0,14 * *$ & - & $0,11 *$ & $4,37^{\mathrm{ns}}$ & $8,38 * *$ & - & $8,54 *$ \\
\hline \multirow[t]{2}{*}{$\mathrm{CV}(\%)$} & 6,76 & 10,42 & - & 9,79 & 8,31 & 8,00 & - & \\
\hline & \multicolumn{8}{|c|}{1996} \\
\hline Rem. das folhas da haste principal & $4,95 \mathrm{a}$ & $5,77 \mathrm{a}$ & $5,72 \mathrm{a}$ & $5,73 \mathrm{a}$ & $30,00 \mathrm{a}$ & $35,61 \mathrm{a}$ & $36,00 \mathrm{a}$ & $36,25 \mathrm{a}$ \\
\hline Rem. das folhas de ramos frutíferos & $5,18 \mathrm{~b}$ & $6,21 b$ & $6,19 b$ & $6,24 b$ & $32,70 \mathrm{a}$ & $40,53 a$ & $41,30 b$ & $41,70 \mathrm{~b}$ \\
\hline Sem remoção de folhas & $5,42 b$ & $6,57 \mathrm{c}$ & $6,33 b$ & $6,54 \mathrm{~b}$ & $33,95 \mathrm{a}$ & $40,93 \mathrm{a}$ & $41,80 \mathrm{~b}$ & $42,30 \mathrm{~b}$ \\
\hline $\mathrm{F}$ & $5,00 *$ & $15,00 *$ & $5,00^{*}$ & $12,00 *$ & $1,17^{\mathrm{ns}}$ & $3,48^{*}$ & $3,78^{*}$ & $3,82 *$ \\
\hline $\mathrm{CV}(\%)$ & 7,33 & 5,08 & 8,37 & 6,56 & 13,40 & 12,86 & 13,17 & 13,45 \\
\hline
\end{tabular}

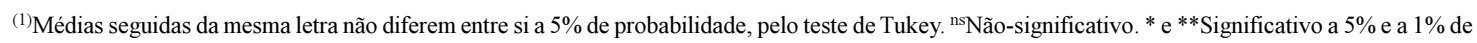
probabilidade, respectivamente. 
frutificação. De acordo com Mauney $(1979,1986)$ isto ocorre devido à facilidade com que os assimilados fotossintéticos chegam a estes frutos (Figura 1). Os resultados deste trabalho estão em consonância com os obtidos por Oosterhuis \& Urwiler (1988), que afirmaram que a importância das folhas principais está condicionada ao estádio de desenvolvimento da planta do algodão.

No segundo experimento, em 1996 (Tabela 1), o diâmetro caulinar foi afetado pela remoção das folhas da haste, dos 40 aos 110 DAE, enquanto a altura da planta foi reduzida a partir dos 80 DAE. Estes resultados assemelham-se aos encontrados por Oosterhuis \& Urwiler (1988), que verificaram que a remoção das folhas da haste principal provoca redução no rendimento da planta de algodão. Os resultados dos dois experimentos indicam que as folhas da haste principal exercem maior influência no desenvolvimento do diâmetro caulinar e na altura

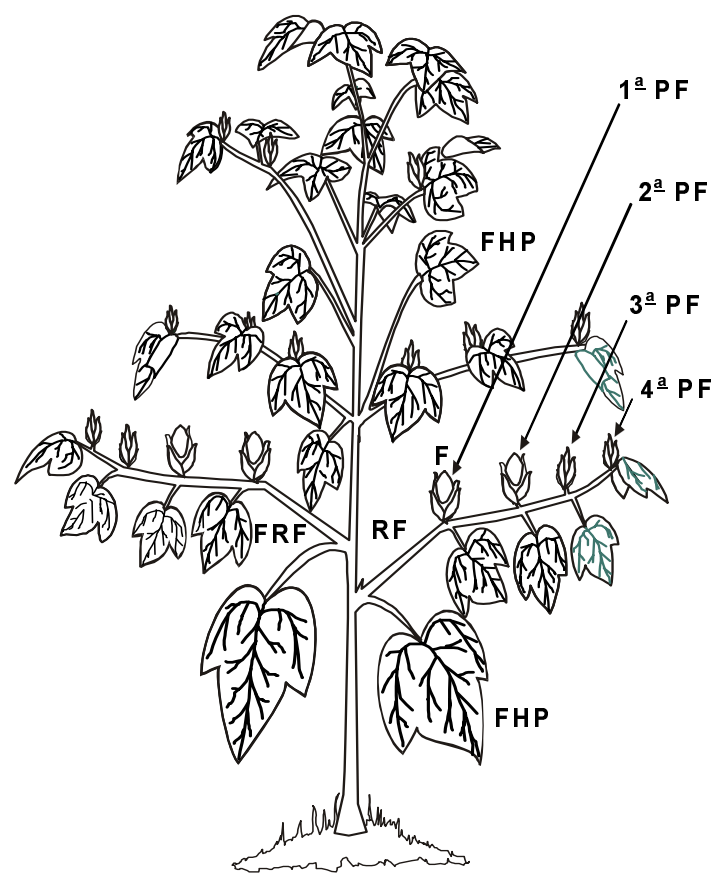

Figura 1. Esquema da frutificação do algodoeiro herbáceo evidenciando-se as folhas da haste principal (FHP), folhas dos ramos frutíferos (FRF), ramos frutíferos (RF) e os frutos (F) nos ramos frutíferos mostrando as posições frutíferas (PF). da planta do que as folhas dos ramos frutíferos. Soares \& Busoli (1996) e Soares et al. (1999) fizeram a mesma observação em relação ao diâmetro caulinar. A fitomassa, a produção de capulhos e o número de frutos do tratamento com remoção das folhas da haste principal foram inferiores aos do tratamento sem remoção (Tabela 2). Isso ocorreu, provavelmente, pelo fato de as folhas vegetativas viverem mais e possuírem maior área foliar que as frutíferas (Hearn \& Constable, 1984). Essas folhas são as mais importantes, pois além de nutrirem o ramo em crescimento fornecem a maior parte dos assimilados para os dois primeiros frutos do ramo frutífero, que são salientados por Mauney (1986) como os principais responsáveis pela produção da planta de algodão (Figuras 1 e 2). No segundo experimento ocorreu redução no número de frutos, em relação a 1995, provavelmente em decorrência do sombreamento nas plantas e conseqüente redução na capacidade fotossintética (Beltrão \& Azevedo, 1993).

Nos levantamentos de área foliar efetuados aos 40 DAE, os tratamentos não foram diferentes; porém, aos 60, 80 e $110 \mathrm{DAE}$, o tratamento com remoção de folhas da haste principal diferiu do tratamento sem remoção de folhas, observando-se, aos 110 DAE, diferença estatística entre os três tratamentos, com uma redução da área foliar em torno de $50 \%$ no tratamento com remoção de folhas da haste principal, e de $40 \%$ no tratamento com remoção das folhas do ramo frutífero em relação ao controle (Tabela 3 ).

Tabela 2. Efeito da remoção das folhas da haste principal e dos ramos frutíferos sobre fitomassa ( $\mathrm{g} / \mathrm{planta}$ ), produção capulhos (g/planta) e número de frutos de algodoeiro CNPA 7H, em experimentos realizados em 1995 e $1996^{(1)}$.

\begin{tabular}{lllll}
\hline Tratamento & $\begin{array}{l}\text { Fitomassa } \\
(1995)\end{array}$ & $\begin{array}{l}\text { Capulhos } \\
(1996)\end{array}$ & \multicolumn{2}{l}{ Número de frutos } \\
& 1995 & 1996 \\
\hline $\begin{array}{l}\text { Rem. das folhas da } \\
\text { haste principal }\end{array}$ & $55,56 \mathrm{a}$ & $13,99 \mathrm{a}$ & $5,80 \mathrm{a}$ & $2,50 \mathrm{a}$ \\
$\begin{array}{l}\text { Rem. das folhas de } \\
\text { ramo frutífero }\end{array}$ & $72,61 \mathrm{~b}$ & $18,49 \mathrm{ab}$ & $6,90 \mathrm{ab}$ & $3,00 \mathrm{ab}$ \\
$\begin{array}{l}\text { Sem remoção de } \\
\text { folha }\end{array}$ & $79,95 \mathrm{~b}$ & $20,79 \mathrm{~b}$ & $8,30 \mathrm{~b}$ & $3,90 \mathrm{~b}$ \\
\hline $\mathrm{F}$ & & & & \\
$\mathrm{CV}(\%)$ & $10,86^{*}$ & $4,81^{*}$ & $2,13^{*}$ & $0,92^{*}$ \\
& 17,30 & 28,11 & 27,28 & 29,39 \\
\hline
\end{tabular}

(1)Médias seguidas da mesma letra não diferem entre si a $5 \%$ de probabilidade, pelo teste de Tukey. $*$ Significativo a $5 \%$ de probabilidade. 


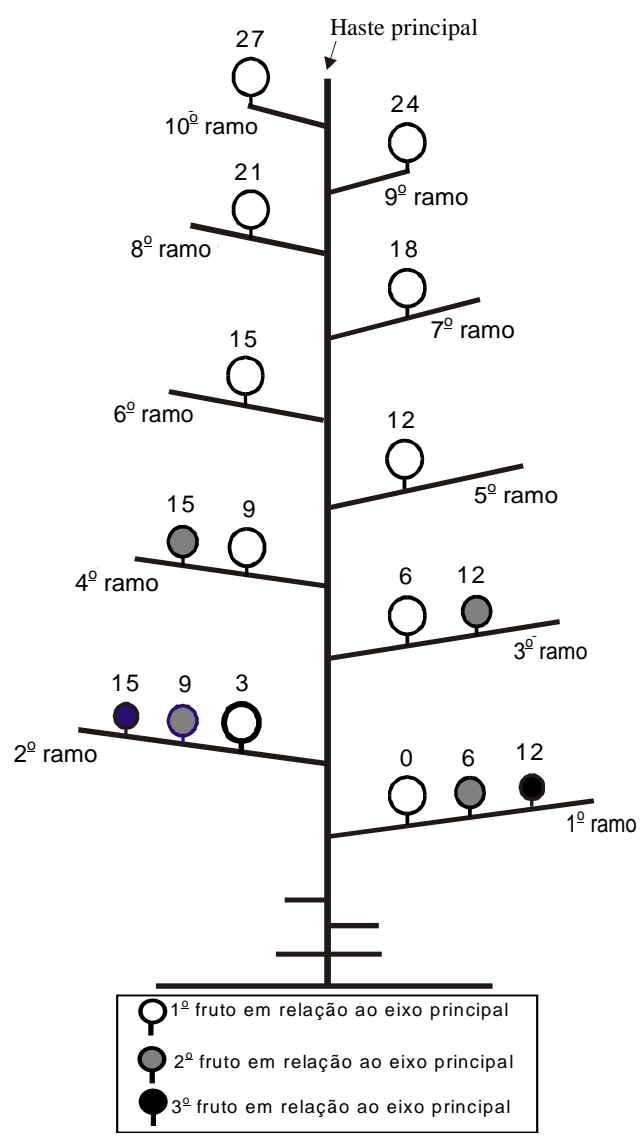

Figura 2. Esquema de uma planta de algodoeiro com florescimento em intervalos de três dias, entre os primeiros frutos de dois ramos seqüenciais, e de seis dias, entre dois frutos seqüenciais no mesmo ramo, de acordo com Soares \& Busoli (1996).

Tabela 3. Área foliar, aos 40,60, 80 e 110 dias após a emergência (DAE), em algodoeiro submetido a diferentes tratamentos, em 1995 e $1996^{(1)}$.

\begin{tabular}{lcrrr}
\hline Tratamento & \multicolumn{4}{c}{ Área foliar } \\
\cline { 2 - 5 } & 40 DAE & 60 DAE & 80 DAE & 110 DAE \\
\hline $\begin{array}{l}\text { Rem. das folhas } \\
\text { da haste principal }\end{array}$ & $608,34 \mathrm{a}$ & $850,08 \mathrm{a}$ & $1.190,86 \mathrm{a}$ & $809,28 \mathrm{a}$ \\
$\begin{array}{l}\text { Rem. das folhas } \\
\text { de ramo frutífero }\end{array}$ & $631,41 \mathrm{a}$ & $1.085,63 \mathrm{ab}$ & $1.486,55 \mathrm{~b}$ & $1.174,00 \mathrm{~b}$ \\
$\begin{array}{l}\text { Sem remoção de } \\
\text { folha }\end{array}$ & $794,23 \mathrm{a}$ & $1.352,00 \mathrm{~b}$ & $1.631,00 \mathrm{~b}$ & $1.619,14 \mathrm{c}$ \\
\hline $\mathrm{F}$ & $4,12^{\mathrm{ns}}$ & $5,84^{*}$ & $8,14^{*}$ & $20,94^{*}$ \\
$\mathrm{CV}(\%)$ & 25,91 & 29,97 & 17,31 & 23,33 \\
\hline
\end{tabular}

(1)Médias seguidas da mesma letra não diferem entre si a $5 \%$ de probabilida-

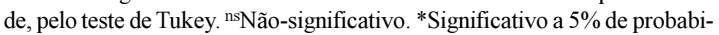
lidade.
De acordo com Eaton \& Ercle (1965), desfolhamentos de $50 \%$ em plantas de algodão, até a formação dos frutos, resultam em redução de até $14 \%$ na produção. O algodoeiro possui crescimento seqüencial e bem definido, onde os intervalos de crescimento e florescimento vertical e horizontal são estimados em três e seis dias respectivamente, isto é, a cada três dias haverá a emissão de um novo ramo frutífero ou simpodial, e a cada seis dias haverá a emissão de uma nova estrutura frutífera (botão floral) nesse mesmo ramo (Figura 2) (Soares et al., 1999). Portanto, as folhas da haste principal são responsáveis pela produção e desenvolvimento vegetativo da planta de algodão.

\section{Conclusão}

A remoção das folhas da haste principal do algodoeiro afeta o diâmetro caulinar, a altura das plantas, a fitomassa, e a produção e número de frutos.

\section{Referências}

ASHLEY, D. A.; DOSS, B. D.; BENNETT, O. L. Relation of cotton leaf area index to plant growth and fruiting. Agronomy Journal, Madison, v. 57, p. 61-64, 1965.

BELTRÃO, N. E. de M.; AZEVEDO, D. M. P. de. Defasagem entre as produtividades real e potencial no algodoeiro herbáceo: limitações morfológicas e ambientais. Campina Grande : Embrapa-CNPA, 1993. 108 p. (Documentos, 31).

BLEICHER, E.; MELO, A. B. P. de; JESUS, F. M. M. de; FERRAZ, C. T. Distribuição vertical de lagartas de Alabama argillacea (Hübner, 1818) (Lepidoptera: Noctuidae) em plantas de algodoeiro herbáceo. Anais da Sociedade Entomológica do Brasil, Jaboticabal, v. 1, n. 12 , p. 117-121, 1983.

CALAFIORI, M. H.; ALVAREZ, E. J.; GEORGETTI, C. L.; DURIGAN, H. J.; MENDES, E. Controle do curuquerê do algodoeiro (A. argillacea, Hub. 1818) em dois ensaios de campo com utilização de piretróide sintético em redução de dosagens. Ecossistema, Campinas, v. 11, p. $24-30,1986$.

CAVALCANTE, R. D. O combate ao curuquerê do algodoeiro. Fortaleza : Embrapa-CNPA, 1977. 3 p. (Boletim Técnico, 239).

CAVAlCANTE, R. D.; CAVAlCANTE, M. L. S. Duas sérias pragas do algodoeiro no Ceará. Fortaleza : EPACE, 1981. 8 p. (Comunicado Técnico, 6). 
EATON, F. M.; ERCLE, D. R. Effects of shade and partial defoliation on carbohydrate level and growth, fruiting and fiber properties of cotton plants. Plant Physiology, Rockville, v. 29, p. 39-49, 1965.

HEARN, A. B.; CONSTABle, G. A. Cotton. In: GOLDSWORTH, P. R.; FISHER, N. M. (Ed.). The physiology of tropical field crops. New York : J. Wiley, 1984. p. $495-527$.

JENSEN, R. G. The biochemistry of photosynthesis. In: MAUNEY, J. R.; STEWART, J. M. (Ed.). Cotton physiology. Memphis : The Cotton Foundation, 1986. p. $157-182$.

MAUNEY, J. R. Production of fruiting points. In: COTTON PHYSIOLOGY CONFERENCE, 33., 1979, Memphis. Proceedings... Memphis : National Cotton Council, 1979. p. 256-261.

MAUNEY, J. R. Vegetative growth and development of fruiting. In: MAUNEY, J. R.; STEWART, J. M. (Ed.). Cotton physiology. Memphis : The Cotton Foundation, 1986. p. 11-28.

OOSTERHUIS, D. M.; URWILER, M. J. Cotton main stem leaves in relation to vegetative and yield. Agronomy Journal, Madison, v. 80, p. 65-68, 1988.
PIMENTEL-GOMES, F. Curso de Estatística Experimental. 12. ed. São Paulo : Nobel, 1987. 467 p.

SILVA, A. L. da; PRADO, P. C. N. do; CUNHA, H. F. da. Manejo das principais pragas do algodoeiro em Goiás. Goiânia : EMGOPA, 1981. 19 p. (Circular Técnica, 2).

SOARES, J. J.; BUSOLI, A. C. Efeito dos reguladores de crescimento vegetal nas características agronômicas do algodoeiro e no controle de insetos. Pesquisa Agropecuária Brasileira, Brasília, v. 31, n. 1, p. 37-41, jan. 1996.

SOARES, J. J.; JÁCOME, A. G.; SOUSA, J. G.; OLIVEIRA, R. H.; WANDERLEY, D. S. Influência do desfolhamento simulados pelo ataque do curuquerê no desenvolvimento vegetativo e no rendimento do algodoeiro. Campina Grande : Embrapa-CNPA, 1997. 6 p. (Comunicado Técnico, 61).

SOARES, J. J.; LARA, F. M.; SILVA, C. A. D. da; ALMEIDA, R. P. de; WANDERLEY, D. S. Influência da posição do fruto na planta sobre a produção do algodoeiro. Pesquisa Agropecuária Brasileira, Brasília, v. 34, n. 5, p. 755-759, maio 1999.

WULLSCHLEGER, S. D.; OOSTERHUIS, D. M. Photosynthetic carbon production and use by developing cotton leaves and boll. Crop Science, Madison, v. 30, p. 1259-1264, 1990. 